\title{
Highly Active AuCu-Based Catalysts for Acetylene Hydrochlorination Prepared Using Organic Aqua Regia
}

\author{
Haihua He ${ }^{1,2}{ }^{,}$Jia Zhao ${ }^{1, *}$, Bolin Wang ${ }^{1}$, Yuxue Yue ${ }^{1}$, Gangfeng Sheng ${ }^{1}$, Qingtao Wang ${ }^{1}$, \\ $\mathrm{Lu} \mathrm{Yu}{ }^{1}$, Zhong-Ting $\mathrm{Hu}^{3}$ and Xiaonian $\mathrm{Li}^{1}{ }^{1} *$ \\ 1 Industrial Catalysis Institute, Laboratory Breeding Base of Green Chemistry-Synthesis Technology, \\ Zhejiang University of Technology, Hangzhou 310014, China; hehaihua2002@jhc.edu.cn (H.H.); \\ wbl501028@outlook.com (B.W.); yueyuxue@outlook.com (Y.Y.); shenggangfeng12@outlook.com (G.S.); \\ qtwang@zjut.edu.cn (Q.W.); yuluuni2014@gmail.com (L.Y.) \\ 2 Pharmaceutical and Material Engineering School, Jin Hua Polytechnic, Jinhua 321007, China \\ 3 College of Environment, Zhejiang University of Technology, Hangzhou 310014, China; zthu@zjut.edu.cn \\ * Correspondence: jiazhao@zjut.edu.cn (J.Z.); xnli@zjut.edu.cn (X.L.); Tel.: +86-571-88871565 (J.Z.); \\ $+86-571-88320002$ (X.L.)
}

Received: 11 March 2019; Accepted: 18 April 2019; Published: 22 April 2019

\begin{abstract}
Development of a sustainable process for designing and synthesising an active and stable catalyst for hydrochlorination of acetylene is challenging, yet crucial, for industrial vinyl chloride monomer (VCM) production. Herein, direct synthesis of bimetallic AuCu catalysts using organic aqua regia (OAR) preparation methods was investigated. In comparison with conventional aqua regia (AR), bimetallic $\mathrm{AuCu}$ catalysts synthesised from OAR exhibit enhanced activity and stability. After careful characterisation of the catalyst samples using X-ray diffraction patterns (XRD), Scanning transmission electron microscopy (STEM), X-ray photoelectron spectroscopy (XPS), and Temperature-programmed desorption (TPD), this observation was justified for the following reasons: 1) the existence of sulphur and nitrogen atoms stabilised the cationic Au active sites, and 2) OAR helped to sustain the function of the $\mathrm{Cu}$ promotor by stabilising it. Advanced understanding on the importance of promoter stability has unveiled new perspectives for this research area.
\end{abstract}

Keywords: acetylene hydrochlorination; $\mathrm{AuCu}$ catalyst; organic aqua regia (OAR)

\section{Introduction}

Acetylene hydrochlorination $\left(\mathrm{C}_{2} \mathrm{H}_{2}+\mathrm{HCl} \rightarrow \mathrm{CH}_{2}=\mathrm{CHCl}, \triangle \mathrm{H}=-124.8 \mathrm{~kJ} / \mathrm{mol}\right)$ is an important reaction for producing vinyl chloride monomer (VCM) for chemical processing [1]. However, the most universal catalyst for this reaction, mercury chloride, is highly volatile, toxic and persistent $[2,3]$, and can pose a serious threat to human health and the environment, thus non-mercury analogues are urgently required. To obtain a promising and practical non-mercury alternative, various catalysts include noble metals [4-20], non-noble metals [21-24] and even non-metal materials [25-32] have been investigated. Pioneering work by Hutchings revealed that gold in the ionic state possesses a unique catalytic activity on the hydrochlorination reaction of acetylene [4-10]. Thereafter, catalysts with high efficiency in the form of $\mathrm{Au} / \mathrm{carbon}$ demonstrate that the gold is feasible as a substitute for the poisonous $\mathrm{HgCl}_{2}$ catalyst [33-40]. Despite the impressive success achieved, the easy deactivation of $\mathrm{Au}^{3+}$ catalyst originated from its high standard electrode potential [41,42] and sintering of the catalyst [12], which largely restrains its application in industry.

The design of the catalyst has so far been the main approach to improve the reaction efficiency of acetylene hydrochlorination. As a potential replacement for Hg-based catalyst, a variety of efforts have 
been tried to improve the catalytic performance of Au-based catalysts, common strategies include 1 . Doping the catalyst supports with heteroatoms such as N [43-46], S [47], and B [48]; 2. Addition of a second metal like Cs [49,50], Co [51], La [52], Ni [53], Ce [54], In [55] or Cu [56-63]. Bimetallic AuCu catalysts showing satisfying catalytic performance are among the most attractive catalytic systems discovered so far, but like all the other Au-based catalysts, it still suffers from its limited lifetime caused by reduction of cationic $\mathrm{Au}^{3+}$ to metallic $\mathrm{Au}^{0}$. Therefore, here we aim to gain a deeper understanding on the effect of promoters to facilitate the development of catalytic systems with enhanced performance.

In our previous study, instead of using conventional aqua regia (AR), we have successfully synthesised an active carbon (AC)-supported Au-based catalyst using a new organic aqua regia (OAR) prepared by adding organic compounds to $\mathrm{SOCl}_{2}$ [64]. In this work, we demonstrated that bimetallic $\mathrm{AuCu}$ catalysts can be prepared via this OAR approach. Compared with the synthetic process of the catalyst using aqua regia $(\mathrm{AuCu} / \mathrm{AC}(\mathrm{AR}))$, we find that the $\mathrm{AuCu} / \mathrm{AC}(\mathrm{OAR})$ exhibited a very good catalytic performance. It can be observed from the catalyst characterisation that the OAR preparation method can be helpful to prevent reduction of the active Au species because of the presence of the coordinating abilities of the sulfur. More importantly, mechanistic studies revealed that the OAR can also stabilise $\mathrm{Cu}$ species to sustain the promoting effect of $\mathrm{Cu}$. These results are important for the design of active and stable bimetallic Au-based catalysts.

\section{Materials and Methods}

\subsection{Catalyst Preparation}

Activated carbon (Norit ROX 0.8, Cabot Cor., Boston, MA, USA) was employed as the catalyst support. The $\mathrm{AuCu} / \mathrm{AC}(\mathrm{OAR})$ catalyst was synthetised by using the wet impregnation method and OAR was used as a solvent. In a typical synthesis of the $\mathrm{AuCu}_{1} / \mathrm{AC}(\mathrm{OAR})$ catalyst, $0.1 \mathrm{~mL}$ of $\mathrm{HAuCl}_{4}$ (0.06 gAu/mL, Reagent No.1 Factory of Shanghai Chemical Reagent Co., Ltd., Shanghai, China) and $1 \mathrm{~mL}$ of $\mathrm{CuCl}_{2}(0.03 \mathrm{~g} \mathrm{Cu} / \mathrm{mL}$, Shanghai Titanchem Co., Ltd., Shanghai, China) aqueous solution were injected into $5.4 \mathrm{~mL}$ of OAR (1:10 thionyl chloride $\left(\mathrm{SOCl}_{2}\right.$, AR, Shanghai Ling Feng Reagent Co., Ltd., Shanghai, China): N,N-Dimethylformamide (DMF, AR, Shanghai Ling Feng Reagent Co., Ltd., Shanghai, China)) with a magnetic stirrer. The solution was stirred for $2 \mathrm{~h}$ and then injected into $2.97 \mathrm{~g}$ of activated carbon. The mixture was agitated via stirring and then drying at $110{ }^{\circ} \mathrm{C}$ under vacuum for $16 \mathrm{~h}$. $\mathrm{AuCu} / \mathrm{AC}(\mathrm{OAR})$ catalysts with various $\mathrm{Cu}$ loadings $(0.2 \mathrm{wt} \%$ to $2 \mathrm{wt} \%)$ were synthesised using the same synthetic procedures, varying the amount of $\mathrm{CuCl}_{2}$ solution added. Au loading was kept constant in all catalysts at $0.2 \mathrm{wt} \%$, and the obtained bimetallic $\mathrm{AuCu}$ catalysts were labeled as $\mathrm{AuCu}_{\mathrm{x}} / \mathrm{AC}(\mathrm{OAR})$ with the $\mathrm{x}$ equivalent to the $\mathrm{Cu}$ loading $(0.2,0.6,1$ and $2 \mathrm{wt} \%)$. For comparison, the bimetallic $\mathrm{AuCu}_{1} / \mathrm{AC}(\mathrm{AR})$ catalyst was also prepared with the same procedure mentioned above, but used aqua regia (1:3 $\mathrm{HNO}_{3}$ ( $>68 \%$, Shanghai Ling Feng Reagent Co., Ltd., Shanghai, China ): $\mathrm{HCl}$ ( $>37 \%$, Shanghai Ling Feng Reagent Co., Ltd., Shanghai, China)) as a solvent. This was used as a reference catalyst.

\subsection{Catalyst Characterisation}

Morphology and microstructures of the catalysts were characterised using transmission electron microscopy (TEM). A Tecnai G2 F30 S-Twin (Thermo Scientific, Waltham, MA, USA) electron microscope was used for TEM observation. X-ray photoelectron spectroscopy (XPS) analysis was performed with a Kratos AXIS Ultra DLD (Shimadzu Corp., Tokyo, Japan) apparatus, equipped with monochromatised aluminum X-ray source, and passed energy with an electron analyzer of $40 \mathrm{eV}$. The spectra were corrected for charging using the $\mathrm{C} 1 \mathrm{~s}$ binding energy $(\mathrm{BE})$ as the reference at $284.8 \mathrm{eV}$. Brunauer-Emmertt-Teller (BET) specific surface areas were measured using $\mathrm{N}_{2}$ adsorption-desorption at $77 \mathrm{~K}$ in a Micromeritics ASAP 2000 (Micromeritics Instruments Corp., Norcross, GA, USA)apparatus. The TPD experiments were conducted in a tubular quartz reactor. A total of $75 \mathrm{mg}$ of each catalyst sample was initially treated with pure $\mathrm{C}_{2} \mathrm{H}_{2}$ or $\mathrm{HCl}$ at $180{ }^{\circ} \mathrm{C}$ for 30 min after the adsorption, sweeping with pure $\mathrm{Ar}$ 
at gas flow rate of $30 \mathrm{~mL} / \mathrm{min}$ for $60 \mathrm{~min}$ to blow the sample at room temperature $\left(25^{\circ} \mathrm{C}\right)$. Then, a temperature-programmed route was carried out from $25^{\circ} \mathrm{C}$ to $550{ }^{\circ} \mathrm{C}$ at a heating rate of $10^{\circ} \mathrm{C} / \mathrm{min}$.

\subsection{Catalytic Test}

The catalytic performance of the above-mentioned catalysts were measured in a fixed bed microreactor in which $0.2 \mathrm{~g}$ of sample mixed with $0.3 \mathrm{~g}$ quartz sand was supported. A reaction gas with a mixture of $\mathrm{C}_{2} \mathrm{H}_{2}$ and $\mathrm{HCl}$ was used to give a fed volume ratio $\mathrm{V}(\mathrm{HCl}) / \mathrm{V}\left(\mathrm{C}_{2} \mathrm{H}_{2}\right)$ of 1.2 and a space velocity of $1480 \mathrm{~h}^{-1}$. The effluent gas was detected on-line with a Fuli 9790 GC (Zhejiang Fuli Co., Ltd., Wenling, China). Prior to analysis, the reaction products were first passed through an absorption vessel containing $\mathrm{NaOH}$ solution to remove the unreacted hydrogen chloride.

\section{Results and Discussion}

\subsection{Optimisations for the Bimetallic Au-Based Catalysts}

Catalytic performance of $\mathrm{AuCu} / \mathrm{AC}(\mathrm{OAR})$ samples with fixed $\mathrm{Au}$ loading but different $\mathrm{Cu}$ loading $(\mathrm{Cu}$ loading $=0.2,0.6,1,2 \mathrm{wt} \%)$ were assessed to investigate the relationship between $\mathrm{Cu}$ loading and the activity of catalysts (Figure 1a). Acetylene conversion obtained after reacting for $2 \mathrm{~h}$ was increased from $62.3 \%$ to $81.2 \%$ with the $\mathrm{Cu}$ content raised from 0.2 to $1 \mathrm{wt} \%$. Further increase in the $\mathrm{Cu}$ loading from 1 to $2 \mathrm{wt} \%$ had a negative impact on the stability of the catalyst. Therefore, $1 \mathrm{wt} \%$ was determined to be the optimal $\mathrm{Cu}$ loading for the $\mathrm{AuCu} / \mathrm{AC}(\mathrm{OAR})$ catalysts.

To evaluate the effect of the OAR and $\mathrm{Cu}$ promotor on the catalytic performance, acetylene conversions over time for four different catalysts- $\mathrm{AuCu}_{1} / \mathrm{AC}(\mathrm{OAR}), \mathrm{Au} / \mathrm{AC}(\mathrm{OAR}), \mathrm{AuCu}_{1} / \mathrm{AC}(\mathrm{AR})$ and $\mathrm{Cu} / \mathrm{AC}(\mathrm{OAR})$ were recorded for comparison (Figure $1 \mathrm{~b})$. $\mathrm{AuCu}_{1} / \mathrm{AC}(\mathrm{OAR})$ had the highest catalytic efficiency and unsurpassed stability, which affirmed that the OAR and $\mathrm{Cu}$ promotor had a stabilising effect on the catalysts and could effectively improve the catalytic activity of them. Low acetylene conversion of the $\mathrm{Cu} / \mathrm{AC}(\mathrm{OAR})$ catalyst demonstrated that $\mathrm{Cu}^{2+}$ had negligible catalytic activity towards the hydrochlorination reaction, thus $\mathrm{Cu}^{2+}$ was functioning mainly as a promotor. For the catalysts tested, all of them were highly selective to VCM (Figure 1c), and the side products 1,2-dichloroethane and chlorinated oligomers were present in trace amounts only.

In comparison with other literature on catalytic systems with respect to their corresponding reaction conditions, the leading position of our optimised catalytic system $\mathrm{AuCu}_{1} / \mathrm{AC}(\mathrm{OAR})$ was confirmed (Figure 1d). Space-time yield (STY, $\left.\operatorname{mol}_{\mathrm{VCM}} /\left(\mathrm{mol}_{\mathrm{Au}} \cdot \mathrm{s}\right)\right)$ results of VCM calculated for $\mathrm{AuCu}_{1} / \mathrm{AC}(\mathrm{OAR})$ was the highest among those reported in the literature on catalytic systems. Note that the STY of $\mathrm{AuCu}_{1} / \mathrm{AC}(\mathrm{OAR})$ was even higher than the state-of-the-art commercial $\mathrm{Na}_{3} \mathrm{Au}\left(\mathrm{S}_{2} \mathrm{O}_{3}\right) / \mathrm{AC}$ catalyst with a Au loading of $0.1 \mathrm{wt} \%$ [65], indicating that the practical application of $\mathrm{AuCu}_{1} / \mathrm{AC}(\mathrm{OAR})$ was highly probable. Moreover, the catalytic performance of this work and others are also listed in Table S1, which further indicates the potential application value of the catalyst $\mathrm{AuCu}_{1} / \mathrm{AC}(\mathrm{OAR})$. 

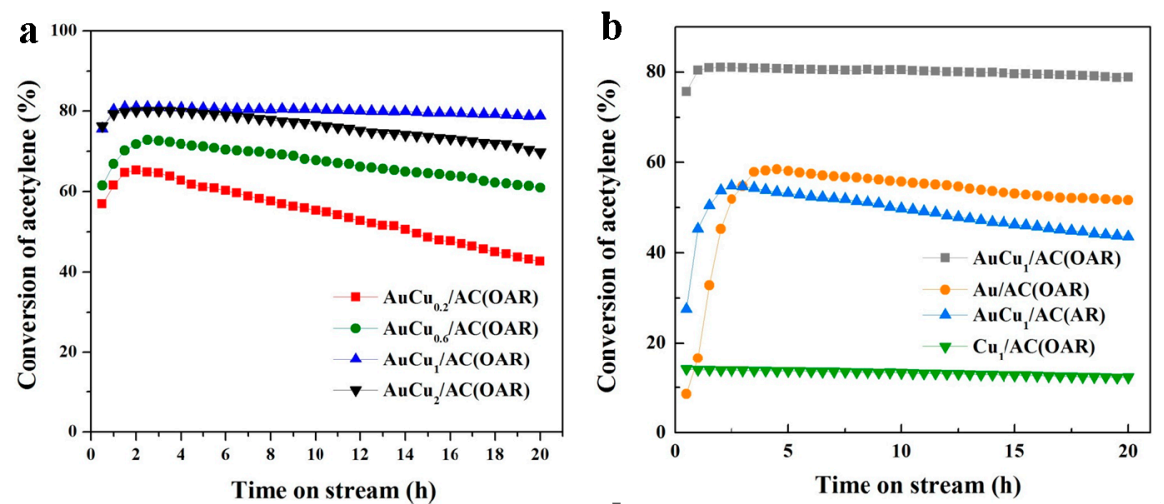

c

d
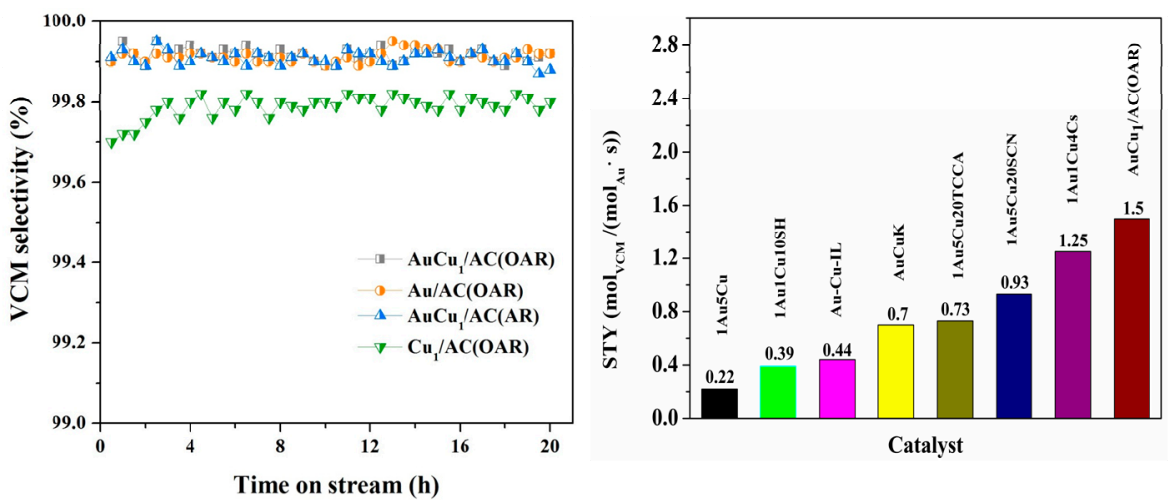

Figure 1. (a) The effect of $\mathrm{Cu}$ addition on the catalytic performance of $\mathrm{AuCu} / \mathrm{AC}(\mathrm{OAR})$ catalysts. (b) Conversion of $\mathrm{C}_{2} \mathrm{H}_{2}$ and (c) selectivity to VCM in hydrochlorination of acetylene over $\mathrm{AuCu} / \mathrm{AC}(\mathrm{OAR})$, $\mathrm{AuCu}_{1} / \mathrm{AC}(\mathrm{AR}), \mathrm{Au} / \mathrm{AC}(\mathrm{OAR})$ and $\mathrm{Cu}_{1} / \mathrm{AC}(\mathrm{OAR})$. (d) The STY values for different bimetallic $\mathrm{AuCu}$ catalytic systems: $1 \mathrm{Au} 5 \mathrm{Cu}$ [57], 1Au1Cu10SH [66], Au-Cu-IL [40], AuCuK [58], 1Au5Cu20TCCA [62], 1Au5Cu20SCN [34], 1Au1Cu4Cs [56] and $\mathrm{AuCu}_{1} / \mathrm{AC}(\mathrm{OAR})$. Reaction conditions: $\mathrm{T}=180^{\circ} \mathrm{C}, \mathrm{C}_{2} \mathrm{H}_{2} \mathrm{GHSV}$ $=1480 \mathrm{~h}^{-1}$, feed volume ratio $\mathrm{V}(\mathrm{HCl}) / \mathrm{V}\left(\mathrm{C}_{2} \mathrm{H}_{2}\right)=1.2$.

\subsection{Effect of the $O A R$ on the $A u C u / A C(O A R)$ Catalyst}

Concerning the effect of the preparation method on the morphology of the synthesised catalysts, and the catalyst deactivation during the reaction, high-angle annular dark-field scanning transmission electron microscopy (HAADF-STEM) was performed for both fresh and used bimetallic AuCu catalysts synthesised using OAR and aqua regia, respectively (Figure 2). As shown in Figure 2a,b, the HADDF-STEM images for both fresh $\mathrm{AuCu}_{1} / \mathrm{AC}(\mathrm{OAR})$ and $\mathrm{AuCu}_{1} / \mathrm{AC}(\mathrm{AR})$ catalysts, respectively, display isolated bright dots, which can be attributed to the single $\mathrm{Au}$ and/or $\mathrm{Cu}$ atoms on the $\mathrm{AC}$ support. This result is consistent with Malta [4] and Conte [8] who have proven that the impregnation of $\mathrm{HAuCl}_{4}$ with aqua regia at a nominal total metal loading of $1 \mathrm{wt} \%$ gave a catalyst with atomically dispersed gold in cationic form over the surface of the support and no metallic Au nanoparticles were observed. As shown in Figure S1, EDX analysis indicated the presence of $\mathrm{Au}, \mathrm{Cu}, \mathrm{S}$ and $\mathrm{Cl}$ atoms for $\mathrm{AuCu}_{1} / \mathrm{AC}(\mathrm{OAR})$. Moreover, investigation regarding the stability of catalysts synthesised differently was also conducted. For used $\mathrm{AuCu}_{1} / \mathrm{AC}(\mathrm{OAR})$ (Figure 2c), the HAADF-STEM image indicated white points suggestive of a single-site structure without the significant agglomeration having happened. However, the catalyst synthesised using aqua regia showed lower resistance to the sintering effect during the reaction, and there appeared to be an agglomeration of the Au species to some extent (Figure 2d), with some large particles (diameter $>2 \mathrm{~nm}$ ) being observed. In summary, OAR preparation was proved to be able to inhibit the catalyst sintering during the reaction with a majority of $\mathrm{Au}$ species maintaining single-atom identities. Indeed, operando Extended X-ray absorption fine structure (EXAFS) analysis performed by Malta et al. have demonstrated that the active sites are isolated Au 
ions [4]. The thermally stable single atom $\mathrm{AuCu}_{1} / \mathrm{AC}(\mathrm{OAR})$ exhibited significantly enhanced stability and performance for the hydrochlorination of acetylene.
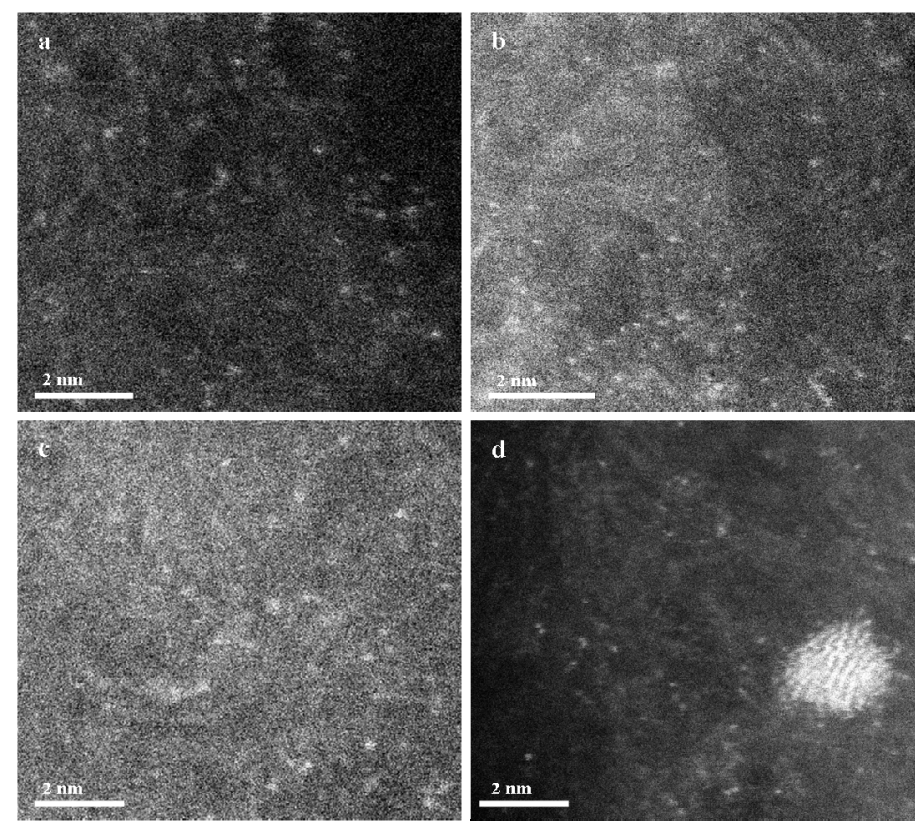

Figure 2. HAADF-STEM images of the fresh and used Au-based catalysts: (a) fresh $\mathrm{AuCu}_{1} / \mathrm{AC}(\mathrm{OAR})$,

(b) fresh $\mathrm{AuCu}_{1} / \mathrm{AC}(\mathrm{AR})$, (c) used $\mathrm{AuCu}_{1} / \mathrm{AC}(\mathrm{OAR})$ and (d) used $\mathrm{AuCu}_{1} / \mathrm{AC}(\mathrm{AR})$.

XPS analysis was employed to inspect the chemical composition of the AuCu catalysts (Table 1 ) for both fresh and used catalysts, and found that concentrations of sulphur and nitrogen residues detected on the surface of the catalysts prepared using OAR were relatively high with respect to the catalysts prepared using conventional aqua regia. Further investigation into the nitrogen spectra (Figure S2) of the $\mathrm{AuCu}_{1} / \mathrm{AC}(\mathrm{OAR})$ catalyst illustrated that two distinct nitrogen states were present, and these two states are represented by two lines on the spectra, namely oxygenated $\mathrm{N}$ species and pyrrolic $\mathrm{N}$ species $[67,68]$. Besides, two peaks corresponding to two different sulphur states were also observed on the sulfur spectra (Figure S3): the peak at $166.8 \mathrm{eV}$ indicated the presence of $-\mathrm{SO}_{\mathrm{n}}-[69]$, while the peak at $162.7 \mathrm{eV}$ might have originated from Au-S [70]. The stabilising effect of these sulphur and nitrogen residues on the $\mathrm{AuCu}_{1} / \mathrm{AC}(\mathrm{OAR})$ catalyst was also supported by previous literature reports ascribing the enhanced activity and stability of $\mathrm{N}$ and/or S-doped $\mathrm{Au} / \mathrm{AC}$ catalysts in contrast with their unmodified analogues [43-47,71]. Furthermore, comparison between XPS analysis of the fresh and used catalysts showed that neither sulphur nor nitrogen leaching were happening.

Table 1. Surface composition of the Au-based catalysts, determined using XPS.

\begin{tabular}{cccccccc}
\hline \multirow{2}{*}{ Catalysts } & \multicolumn{7}{c}{ Surface Elemental Composition (wt\%) } \\
\cline { 2 - 8 } & $\mathbf{A u 4 f}$ & $\mathbf{C 1 s}$ & $\mathbf{C l 2 p}$ & O1s & S2p & N1s & Cu2p \\
\hline Fresh $\mathrm{AuCu}_{1} / \mathrm{AC}(\mathrm{OAR})$ & 0.22 & 89.68 & 1.95 & 4.42 & 1.35 & 1.41 & 0.97 \\
Fresh $\mathrm{AuCu} / \mathrm{AC}(\mathrm{AR})$ & 0.21 & 91.53 & 2.28 & 4.75 & 0.00 & 0.31 & 0.92 \\
Used $\mathrm{AuCu} / \mathrm{AC}(\mathrm{OAR})$ & 0.19 & 90.07 & 1.89 & 4.33 & 1.25 & 1.32 & 0.95 \\
Used $\mathrm{AuCu} / \mathrm{AC}(\mathrm{AR})$ & 0.20 & 91.33 & 2.54 & 4.65 & 0.00 & 0.36 & 0.92 \\
\hline
\end{tabular}

XPS was also employed to investigate the change of the valence-state of Au (Figure 3), and active cationic $\mathrm{Au}^{3+} / \mathrm{Au}^{+}$species with the relative amount in bimetallic $\mathrm{AuCu}$ catalysts (Table 2). Three Au states with Au 4f $7 / 2$ binding energy (BE) of 84.1, 85.4 and $86.7 \mathrm{eV}$, which were attributed to metallic $\mathrm{Au}^{0}$, low-valent $\mathrm{Au}^{+}$and high-valent $\mathrm{Au}^{3+}$, respectively, were detected. Relative amount of the cationic $\mathrm{Au}$ species in the fresh $\mathrm{AuCu}_{1} / \mathrm{AC}(\mathrm{OAR})$ and $\mathrm{AuCu}_{1} / \mathrm{AC}(\mathrm{AR})$ was $63.4 \%$ and $55.2 \%$, 
respectively; thus, $\mathrm{AuCu}_{1} / \mathrm{AC}(\mathrm{OAR})$ contained more active cationic $\mathrm{Au}$ species than $\mathrm{AuCu} \mathrm{u}_{1} / \mathrm{AC}(\mathrm{AR})$. This observation was owed to the stabilising effect of sulphur atoms on the cationic Au species with a higher valence-state, and it prevented the rapid reduction of those active Au species during catalyst preparation processes and also during the catalytic reaction [65]. As mentioned before, cationic $\mathrm{Au}$ species can be reduced to $\mathrm{Au}^{0}$ during the reaction leading to catalyst deactivation, for $\mathrm{AuCu}_{1} / \mathrm{AC}(\mathrm{AR})$ catalysts, the percentage composition of the cationic Au species in used was expressively from $55.2 \%$ (Table 2, fresh $\mathrm{AuCu}_{1} / \mathrm{AC}(\mathrm{AR})$ ) to 31.6\% (Table 2, used $\mathrm{AuCu}_{1} / \mathrm{AC}(\mathrm{AR})$ ), whereas for $\mathrm{AuCu}_{1} / \mathrm{AC}(\mathrm{OAR})$, the decrease was less dramatic (63.4\% to 48.2\%, Table 2, fresh and used $\left.\mathrm{AuCu}_{1} / \mathrm{AC}(\mathrm{OAR})\right)$, which can serve as further evidence to support the fact that OAR synthetic methods can restrain the reduction of cationic Au species, both during the preparation and using processes.
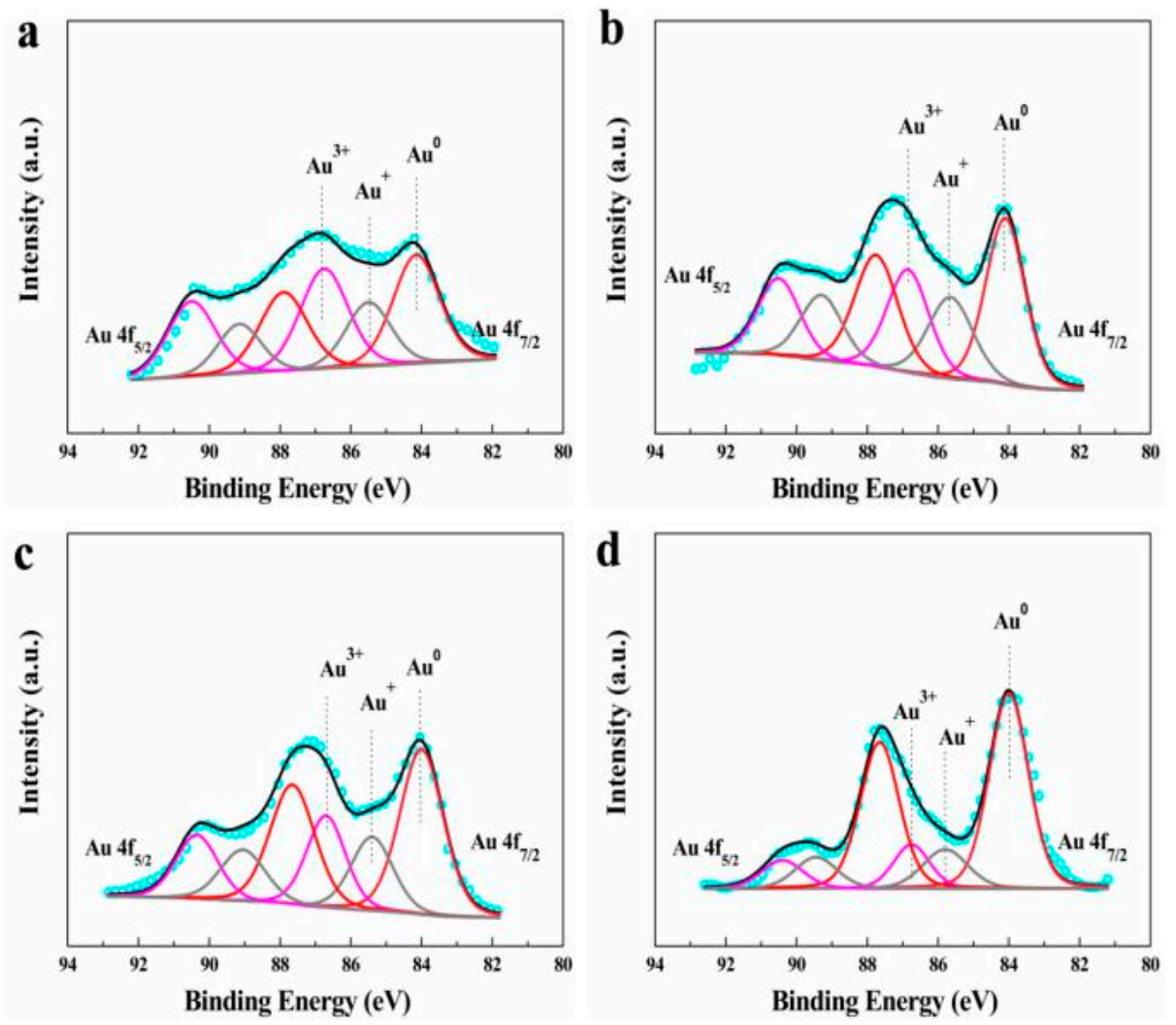

Figure 3. XPS spectrum and simulation for the samples: (a) fresh $A u C u_{1} / A C(O A R)$, (b) used $\mathrm{AuCu}_{1} / \mathrm{AC}(\mathrm{OAR}),(\mathrm{c})$ fresh $\mathrm{AuCu}_{1} / \mathrm{AC}(\mathrm{AR})$ and (d) used $\mathrm{AuCu}_{1} / \mathrm{AC}(\mathrm{AR})$.

Table 2. Quantification and identification of Au species over fresh and used bimetallic $\mathrm{AuCu} / \mathrm{AC}$ catalysts from XPS data.

\begin{tabular}{ccccccc}
\hline \multirow{2}{*}{ Catalysts } & \multicolumn{3}{c}{$\mathbf{A u}$ Species (\%) } & \multicolumn{3}{c}{ Binding Energies (eV) } \\
\cline { 2 - 7 } & $\mathbf{A u}^{\mathbf{3 +}}$ & $\mathbf{A u}^{+}$ & $\mathbf{A u}^{\mathbf{0}}$ & $\mathbf{A u}^{\mathbf{3}}$ & $\mathbf{A u}^{+}$ & $\mathbf{A u}^{\mathbf{0}}$ \\
\hline Fresh $\mathrm{AuCu} / \mathrm{AC}(\mathrm{OAR})$ & 26.8 & 36.6 & 36.6 & 86.7 & 85.4 & 84.1 \\
Fresh $\mathrm{AuCu} / \mathrm{AC}(\mathrm{AR})$ & 29.8 & 25.4 & 44.8 & 87.0 & 85.5 & 84.0 \\
Used $\mathrm{AuCu} / \mathrm{AC}(\mathrm{OAR})$ & 25.8 & 22.4 & 51.8 & 86.8 & 85.6 & 84.1 \\
Used $\mathrm{AuCu} / \mathrm{AC}(\mathrm{AR})$ & 14.5 & 16.1 & 69.4 & 86.8 & 85.8 & 84.0 \\
\hline
\end{tabular}

After investigation of the Au species, similar examinations were conducted on the other metal content in the catalysts, namely the $\mathrm{Cu}$ (II) promotor. Figure 4 presents the XPS spectra of the $\mathrm{Cu} 2 \mathrm{p}$ core levels and the results revealed the presence of $\mathrm{Cu}^{2+}(\mathrm{BE}=934.1 \mathrm{eV})$ and $\mathrm{Cu}^{0}(\mathrm{BE}=931.7 \mathrm{eV})$ states. It can be clearly seen that a certain amount of $\mathrm{Cu}^{0}$ species could also be found from the sample treated using aqua regia or OAR, which can be explained by the adsorption process by $\mathrm{AC}$ being accompanied 
by the reduction of the $\mathrm{Cu}(\mathrm{II})$ species. As can be seen, the results obtained for the $\mathrm{Cu}$ species were very similar to that for $\mathrm{Au}$, where the percentage composition of $\mathrm{Cu}^{2+}$ in $\mathrm{AuCu}_{1} / \mathrm{AC}(\mathrm{OAR})$ (Table 3, fresh and used $\mathrm{AuCu}_{1} / \mathrm{AC}(\mathrm{OAR})$ ) was higher than that in $\mathrm{AuCu}_{1} / \mathrm{AC}(\mathrm{AR})$ (Table 3, fresh and used $\mathrm{AuCu}_{1} / \mathrm{AC}(\mathrm{AR})$ ), with a lower rate of catalyst deactivation (Figure S4). Hence, as well as for cationic $\mathrm{Au}$ species, $\mathrm{N}$ and/or $\mathrm{S}$ also had a stabilising effect on the $\mathrm{Cu}$ species. More importantly, after the reaction, the reduction rate for $\mathrm{Au}^{\mathrm{n}+}(\mathrm{n}=1,3)$ and $\mathrm{Cu}^{2+}$ were $23.97 \%$ and $10.36 \%$ for $\mathrm{AuCu}_{1} / \mathrm{AC}(\mathrm{OAR})$, while it was $44.56 \%$ and $40.74 \%$ for $\mathrm{AuCu}_{1} / \mathrm{AC}(\mathrm{AR})$, respectively (Figure S4). The reduction of cationic $\mathrm{Au}$ species to metallic $\mathrm{Au}$ was accompanied by the corresponding reduction of $\mathrm{Cu}^{2+}$. However, it should be note that the biggest difference between $\mathrm{AuCu}_{1} / \mathrm{AC}(\mathrm{OAR})$ and $\mathrm{AuCu}_{1} / \mathrm{AC}(\mathrm{AR})$ was that $\mathrm{AuCu}_{1} / \mathrm{AC}(\mathrm{OAR})$ had higher nitrogen $(\approx 1.41 \%)$ and sulfur $(\approx 1.35 \%)$ content, which was consistent with the results in Table 1. Obviously, although the content of $\mathrm{Au}^{\mathrm{n}+}(\mathrm{n}=1,3)$ and $\mathrm{Cu}^{2+}$ showed a downward trend for both $\mathrm{AuCu}_{1} / \mathrm{AC}(\mathrm{OAR})$ and $\mathrm{AuCu}_{1} / \mathrm{AC}(\mathrm{AR})$ catalysts in the whole reaction process, which was due to the strong reduction of acetylene, the abundant nitrogen and sulfur species on the surface of $\mathrm{AuCu}_{1} / \mathrm{AC}(\mathrm{OAR})$ catalysts still inhibited the forced reduction of $\mathrm{Au}^{\mathrm{n}+}(\mathrm{n}=1,3)$ and $\mathrm{Cu}^{2+}$ by acetylene. To a certain extent, compared with traditional $\mathrm{AuCu}_{1} / \mathrm{AC}(\mathrm{AR})$ catalysts, the metal active species were stabilised and then improved. In addition, nitrogen and sulfur species not only stabilised the active sites of metals ( $\mathrm{Au}$ and $\mathrm{Cu}$ ), but also redisperse the gold species, which is consistent with the results of TEM (Figure 2). It is well known that $\mathrm{Cu}^{0}$ species work as electron donors and electrons can be transferred from $\mathrm{Cu}$ to $\mathrm{Au}$ in $\mathrm{AuCu}$ systems. The transfer of electrons to the empty orbital of $\mathrm{Au}$, which may not only enhance the electron-donating ability of Au but also strengthen the adsorption capacity of the $\mathrm{HCl}$. In addition, $\mathrm{Cu}^{2+}$ species present in the $\mathrm{AuCu}$ catalysts may worked as an oxidant for reduced $\mathrm{Au}^{0}$ species to regenerate $\mathrm{Au}^{3+}$ with the assistance of the $\mathrm{Cl}^{-}$ligand to stabilise $\mathrm{Au}^{3+}$ species [40].
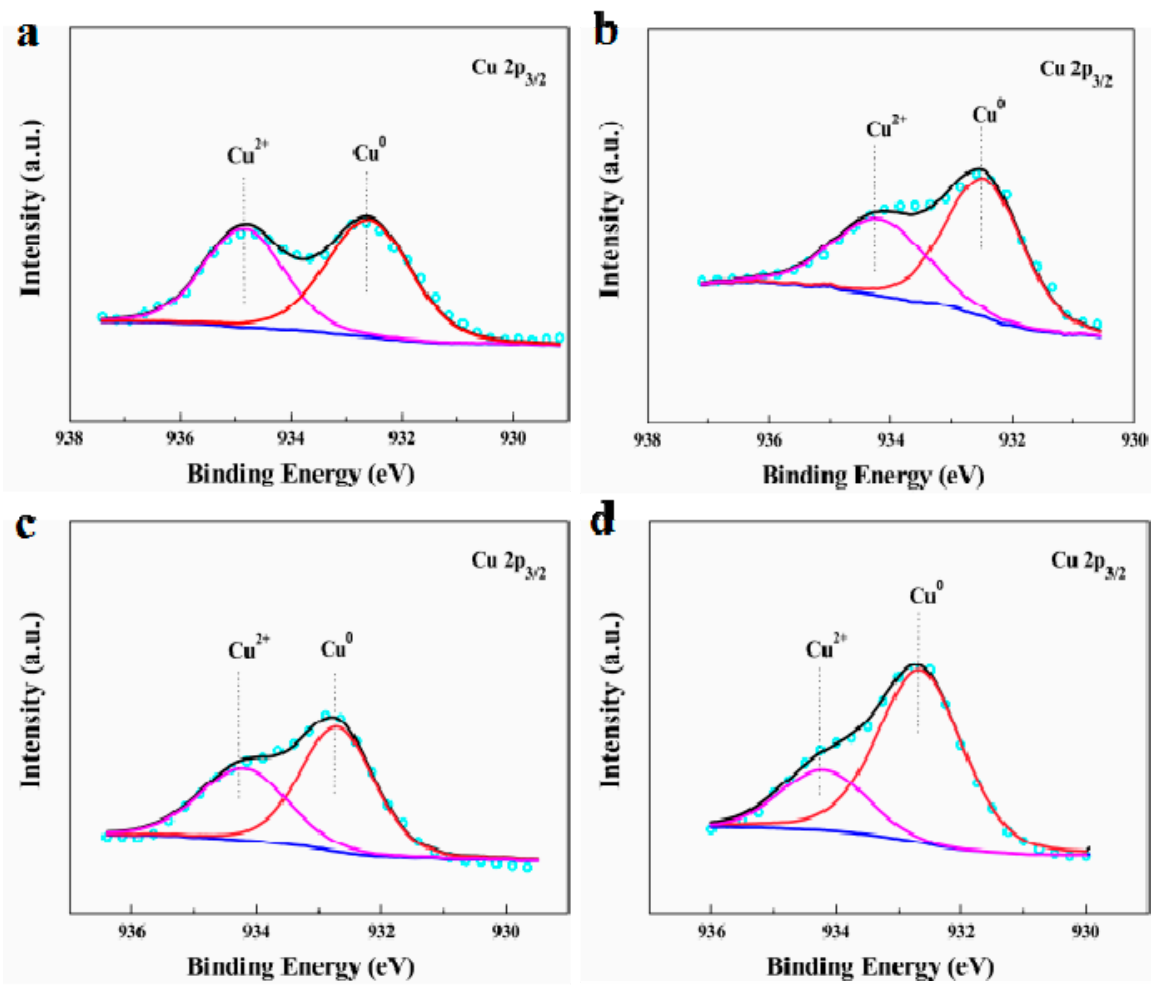

Figure 4. XPS spectra and simulation of the fresh $(\mathbf{a}, \mathbf{c})$ and used $(\mathbf{b}, \mathbf{d}) \mathrm{AuCu}$ catalysts. $(\mathbf{a}, \mathbf{b}) \mathrm{AuCu}_{1} / \mathrm{AC}(\mathrm{OAR})$; (c,d) $\mathrm{AuCu}_{1} / \mathrm{AC}(\mathrm{AR})$. 
Table 3. Quantification and identification of $\mathrm{Cu}$ species over fresh and used bimetallic $\mathrm{AuCu} / \mathrm{AC}$ catalysts from XPS data.

\begin{tabular}{ccccc}
\hline \multirow{2}{*}{ Catalysts } & \multicolumn{2}{c}{$\mathbf{C u}$ Species (\%) } & \multicolumn{2}{c}{ Binding Energies (eV) } \\
\cline { 2 - 5 } & $\mathbf{C u}^{\mathbf{2 +}}$ & $\mathbf{C u}^{\mathbf{0}}$ & $\mathbf{C u}^{\mathbf{2 +}}$ & $\mathbf{C u}^{\mathbf{0}}$ \\
\hline Fresh $\mathrm{AuCu} / \mathrm{AC}(\mathrm{OAR})$ & 44.4 & 55.6 & 934.9 & 932.8 \\
Fresh $\mathrm{AuCu} / \mathrm{AC}(\mathrm{AR})$ & 40.5 & 59.5 & 934.4 & 932.6 \\
Used $\mathrm{AuCu} / \mathrm{AC}(\mathrm{OAR})$ & 39.8 & 60.2 & 934.4 & 932.8 \\
Used $\mathrm{AuCu}{ }_{1} / \mathrm{AC}(\mathrm{AR})$ & 24.0 & 76.0 & 934.2 & 932.6 \\
\hline
\end{tabular}

TPD is an effective characterisation technique for direct comparison of the adsorption capacity of substrates on different catalyst systems [25]. Two desorption peaks are present for acetylene desorption from both $\mathrm{AuCu}_{1} / \mathrm{AC}(\mathrm{AR})$ and $\mathrm{AuCu}_{1} / \mathrm{AC}(\mathrm{OAR})$ catalysts in Figure $5 \mathrm{a}$, where the weaker peaks covering the temperature range of $50-150{ }^{\circ} \mathrm{C}$ correspond to the $\mathrm{C}_{2} \mathrm{H}_{2}$ desorption from the carbon support, while the stronger peaks at temperatures higher than $180{ }^{\circ} \mathrm{C}$ were attributed to the $\mathrm{C}_{2} \mathrm{H}_{2}$ desorption from cationic Au species. Likewise, from Figure $5 b$, there was one adsorbed state of $\mathrm{HCl}$ on the catalysts at $204{ }^{\circ} \mathrm{C}$ for $\mathrm{AuCu}_{1} / \mathrm{AC}(\mathrm{OAR})$. For both the $\mathrm{C}_{2} \mathrm{H}_{2}$ - and $\mathrm{HCl}-\mathrm{TPD}$ spectra, the desorption area of the substrates for $\mathrm{AuCu}_{1} / \mathrm{AC}(\mathrm{OAR})$ was much larger than that of $\mathrm{AuCu}_{1} / \mathrm{AC}(\mathrm{AR})$; nevertheless, the desorption temperature of the substrates for $\mathrm{AuCu}_{1} / \mathrm{AC}(\mathrm{OAR})$ were also different from that for $\mathrm{AuCu}_{1} / \mathrm{AC}(\mathrm{AR})$. The desorption area reveals the amount of substrate adsorbed on the corresponding active sites of the catalysts, where capacity of a catalyst for substrates adsorption is associated with its activity and stability [42]. Furthermore, for the desorption temperature, it is commonly accepted that the weakly bound species usually bear low temperature desorption [25]. These theories in combination with our observations indicated that OAR can undoubtedly aid the generation of catalysts with more active sites and lower the activation energy of acetylene desorption from the catalysts. This can again be explained by the presence of sulphur/nitrogen residues on $\mathrm{AuCu}_{1} / \mathrm{AC}(\mathrm{OAR})$, with the interaction between the residues and Au having a stabilising effect on the active sites, and can also result in different acetylene and hydrogen chloride chemisorption strengths, thus altering the catalytic properties of $\mathrm{AuCu}_{1} / \mathrm{AC}(\mathrm{OAR})$ in contrast to $\mathrm{AuCu}_{1} / \mathrm{AC}(\mathrm{AR})$.
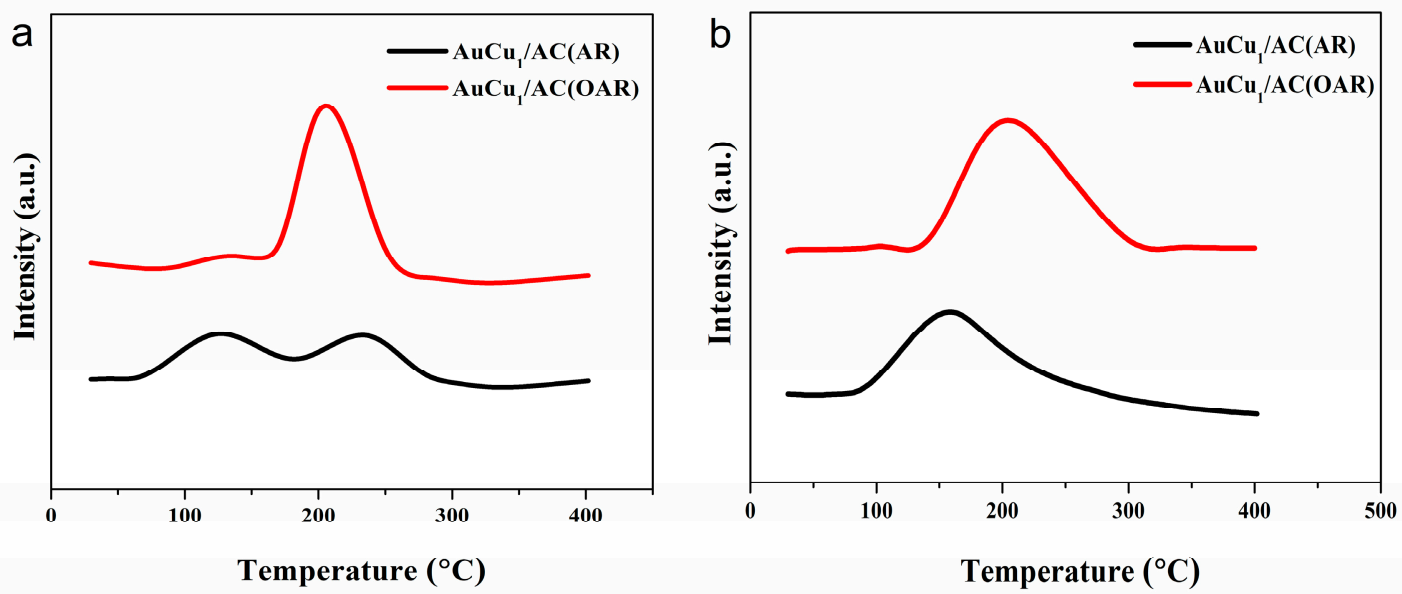

Figure 5. TPD profiles of (a) $\mathrm{C}_{2} \mathrm{H}_{2}$ and (b) $\mathrm{HCl}$ on $\mathrm{AuCu}_{1} / \mathrm{AC}(\mathrm{OAR})$ and $\mathrm{AuCu} \mathrm{u}_{1} / \mathrm{AC}(\mathrm{AR})$ catalysts.

BET analysis was applied to investigate the texture properties of fresh and used catalysts via nitrogen adsorption. Table 4 presents the $\mathrm{S}_{\mathrm{BET}}$ of the fresh and used $\mathrm{AuCu}$ catalysts. It can be seen that after loading the active component, the samples still had a relatively large surface area. However, the used catalysts feature surface areas smaller than those of fresh ones (Table 4). For example, about 16.5\% of the surface area of the $\mathrm{AuCu}_{1} / \mathrm{AC}(\mathrm{AR})$ catalyst was lost after the reaction. Loss of specific surface area probably led to the deposition of coke material, which may result in clogged pores and decreased 
catalyst activity. However, the surface areas of the catalysts lost only $7.6 \%$ for the $\mathrm{AuCu}_{1} / \mathrm{AC}(\mathrm{OAR})$. This result indicates that the amount of coke deposition was significantly reduced using an OAR preparation strategy for the bimetallic $\mathrm{AuCu} / \mathrm{AC}$ catalyst.

Table 4. Surface areas of AC support and bimetallic $\mathrm{AuCu} / \mathrm{AC}$ catalyst samples.

\begin{tabular}{|c|c|c|c|}
\hline \multirow{2}{*}{ Catalysts } & \multicolumn{2}{|c|}{$S_{\text {BET }}\left(m^{2} g^{-1}\right)$} & \multirow{2}{*}{$\Delta S_{\text {BET }}\left(\mathrm{m}^{2} \mathrm{~g}^{-1}\right)$} \\
\hline & Fresh & Used & \\
\hline AC & 1162.1 & / & / \\
\hline $\mathrm{AuCu}_{1} / \mathrm{AC}(\mathrm{AR})$ & 1005.3 & 839.1 & 166.2 \\
\hline $\mathrm{AuCu}_{1} / \mathrm{AC}(\mathrm{OAR})$ & 1067.6 & 986.6 & 81.0 \\
\hline
\end{tabular}

\section{Conclusions}

In conclusion, advantageous usage of OAR in comparison with aqua regia during the preparation process of the catalyst was demonstrated to be able to efficiently improve the catalytic performance of the bimetallic $\mathrm{AuCu} / \mathrm{AC}$ catalysts. The optimised catalyst $\mathrm{AuCu}_{1} / \mathrm{AC}(\mathrm{OAR})$ delivered a stable performance during a 200-h test with a conversion percentage of acetylene reaching more than $98.8 \%$ under industrial reaction conditions. After careful characterisation of fresh and used bimetallic catalysts, we concluded that the influence of OAR preparation methods on the activity and stability of catalysts could be ascribed to the stabilising effect of the residual sulphur and nitrogen species. More importantly, mechanistic studies revealed that the OAR residual could also stabilise cationic $\mathrm{Cu}$ species to sustain the promoting effect of $\mathrm{Cu}(\mathrm{II})$. This work has clearly demonstrated that this route for catalyst design can lead to improved catalytic processes.

Supplementary Materials: The following are available online at http://www.mdpi.com/1996-1944/12/8/1310/s1. Figure S1: EDX spectra of fresh $\mathrm{AuCu}_{1} / \mathrm{AC}(\mathrm{OAR})$ catalyst. Figure S2: High-resolution N 1s spectra of the (a) fresh and $(\mathbf{b})$ used $\mathrm{AuCu}_{1} / \mathrm{AC}(\mathrm{OAR})$ catalyst. Figure S3: High-resolution $S 2 p$ spectra of the (a) fresh and (b) used $\mathrm{AuCu}_{1} / \mathrm{AC}(\mathrm{OAR})$ catalysts. Figure S4: The reduction rate for cationic $\mathrm{Au}$ and $\mathrm{Cu}$ species: (a) $\mathrm{AuCu} / \mathrm{AC}(\mathrm{OAR})$ and (b) $\mathrm{AuCu}_{1} / \mathrm{AC}(\mathrm{AR})$ catalysts. Table S1: Catalytic performance of different AuCu-based catalysts.

Author Contributions: Conceptualisation, J.Z. and X.L.; methodology, B.W. and Z.H.; validation, Y.Y., G.S. and L.Y.; data curation, Q.W.; writing—original draft preparation, H.H.; writing—review and editing, H.H.

Funding: This research was funded by National Natural Science Foundation of China (Project No. 21606199, 21476207) and Zhejiang Province Public Welfare Project (Project No.2017C31116).

Conflicts of Interest: The authors declare no conflict of interest.

\section{References}

1. Schobert, H. Production of acetylene and acetylene-based chemicals from coal. Chem. Rev. 2014, 114, 1743-1760. [CrossRef] [PubMed]

2. Hashmi, A.S.; Hutchings, G.J. Gold catalysis. Angew. Chem. 2006, 45, 7896-7936. [CrossRef] [PubMed]

3. Davies, C.J.; Miedziak, P.J.; Brett, G.L.; Hutchings, G.J. Vinyl chloride monomer production catalysed by gold: A review. Chin. J. Catal. 2016, 37, 1600-1607. [CrossRef]

4. Malta, G.; Kondra, S.A.; Freakley, S.J.; Davies, C.J.; Lu, L.; Dawson, S.; Thetford, A.; Gibson, E.K.; Morgan, D.J.; Jones, W. Identification of single site gold catalysis in acetylene hydrochlorination. Science 2017, 355, 1399-1403. [CrossRef]

5. Nkosi, B.; Adams, M.D.; Coville, N.J.; Hutchings, G.J. Hydrochlorination of Acetylene Using Carbon-Supported Gold Catalysts: A Study of Catalyst Reactivation. J. Catal. 1991, 128, 378-386. [CrossRef]

6. Malta, G.; Freakley, S.J.; Kondrat, S.A.; Hutchings, G.J. Acetylene hydrochlorination using Au/carbon: A journey towards single site catalysis. Chem. Commun. 2017, 53, 11733-11746. [CrossRef] [PubMed]

7. Conte, M.; Carley, A.F.; Hutchings, G.J. Reactivation of a Carbon-supported Gold Catalyst for the Hydrochlorination of Acetylene. Catal Lett. 2008, 124, 165-167. [CrossRef]

8. Conte, M.; Davies, C.; Morgan, D.; Davies, T.; Elias, D.; Carley, A.; Johnston, P.; Hutchings, G.J. Aqua regia activated $\mathrm{Au} / \mathrm{C}$ catalysts for the hydrochlorination of acetylene. J. Catal. 2013, 297, 128-136. [CrossRef] 
9. Liu, X.; Conte, M.; Elias, D.; Lu, L.; Morgan, D.J.; Freakley, S.J.; Johnston, P.; Kiely, C.J.; Hutchings, G.J. Investigation of the active species in the carbon-supported gold catalyst for acetylene hydrochlorination. Catal. Sci. Technol. 2016, 6, 5144-5153. [CrossRef]

10. Conte, M.; Davies, C.J.; Morgan, D.J.; Carley, A.F.; Johnston, P.; Hutchings, G.J. Characterization of Au ${ }^{3+}$ Species in Au/C Catalysts for the Hydrochlorination Reaction of Acetylene. Catal. Lett. 2013, 144, 1-8. [CrossRef]

11. Kaiser, S.K.; Lin, R.; Mitchell, S.; Fako, E.; Krumeich, F.; Hauert, R.; Safonova, O.V.; Kondratenko, V.A.; Kondratenko, E.V.; Collins, S.M. Controlling the speciation and reactivity of carbon-supported gold nanostructures for catalysed acetylene hydrochlorination. Chem. Sci. 2019, 10, 359-369. [CrossRef]

12. Malta, G.; Kondrat, S.A.; Freakley, S.J.; Davies, C.; Dawson, S.; Liu, X.; Lu, L.; Dymkowski, K.; Fernandez-Alonso, F.; Mukhopadhyay, S. Deactivation of a Single-Site Gold-on-Carbon Acetylene Hydrochlorination Catalyst: An X-ray Absorption and Inelastic Neutron Scattering Study. ACS Catal. 2018, 8, 8493-8505. [CrossRef]

13. Zhao, J.; Yue, Y.; Sheng, G.; Wang, B.; Lai, H.; Di, S.; Zhai, Y.; Guo, L.; Li, X. Supported ionic liquid-palladium catalyst for the highly effective hydrochlorination of acetylene. Chem. Eng. J. 2019, 360, 38-46. [CrossRef]

14. Li, P.; Ding, M.; He, L.; Tie, K.; Ma, H.; Pan, X.; Bao, X. The activity and stability of $\mathrm{PdCl}_{2} / \mathrm{C}-\mathrm{N}$ catalyst for acetylene hydrochlorination. Sci. Chi. Chem. 2018, 61, 444-448. [CrossRef]

15. Wang, L.; Wang, F.; Wang, J. Enhanced stability of hydrochlorination of acetylene using polyaniline-modified Pd/HY catalysts. Catal. Commun. 2016, 74, 55-59. [CrossRef]

16. Panova, S.A.; Shestakov, G.K.; Temkin, O.N. Supported liquid-phase rhodium catalyst for acetylene hydrochlorination. J. Chem. Soc. Chem. Commun. 1994, 7, 977. [CrossRef]

17. Mitchenko, S.A.; Khomutov, E.V.; Shubin, A.A.; Shul'ga, Y.M. Catalytic hydrochlorination of acetylene by gaseous $\mathrm{HCl}$ on the surface of mechanically pre-activated $\mathrm{K}_{2} \mathrm{PtCl}_{6}$ salt. J. Mol. Catal. A: Chem. 2004, 212, 345-352. [CrossRef]

18. Sil'chenko, L.A.; Panova, S.A.; Shestakov, G.K.; Temkin, O.N. Acetylene hydrochlorination in Pt(II) complex solutions: II. The kinetics of acetylene hydrochlorination in Pt(II) complex solutions. Kinet. Catal. 1998, 39, 24-28.

19. Mitchenko, S.A.; Khomutov, E.V.; Shubin, A.A.; Shul'ga, Y.M. Mechanochemical Activation of $\mathrm{K}_{2} \mathrm{PtCl}_{6}$ : Heterogeneous Catalyst for Gas-Phase Hydrochlorination of Acetylene. Theor. Exp. Chem. 2003, 39, 255-258. [CrossRef]

20. Zhao, J.; Wang, B.; Yue, Y.; Di, S.; Zhai, Y.; He, H.; Sheng, G.; Lai, H.; Zhu, Y.; Guo, L. Towards a greener approach for the preparation of highly active gold/carbon catalyst for the hydrochlorination of ethyne. J. Catal. 2018, 365, 153-162. [CrossRef]

21. Zhou, K.; Si, J.; Jia, J.; Huang, J.; Zhou, J.; Luo, G.; Wei, F. Reactivity enhancement of N-CNTs in green catalysis of $\mathrm{C}_{2} \mathrm{H}_{2}$ hydrochlorination by a Cu catalyst. RSC Adv. 2014, 4, 7766-7769. [CrossRef]

22. Zhao, W.; Zhu, M.; Dai, B. The Preparation of Cu-g- $\mathrm{C}_{3} \mathrm{~N}_{4} / \mathrm{AC}$ Catalyst for Acetylene Hydrochlorination. Catalysts 2016, 6, 193. [CrossRef]

23. Wang, B.; Lai, H.; Yue, Y.; Sheng, G.; Deng, Y.; He, H.; Guo, L.; Zhao, J.; Li, X. Zeolite Supported Ionic Liquid Catalysts for the Hydrochlorination of Acetylene. Catalysts 2018, 8, 351. [CrossRef]

24. Zhai, Y.; Zhao, J.; Di, X.; Di, S.; Wang, B.; Yue, Y.; Sheng, G.; Lai, H.; Guo, L.; Wang, H. Carbon supported perovskite-like $\mathrm{CsCuCl}_{3}$ nanoparticles $\mathrm{A}$ highly active and cost-effective heterogeneous catalyst in the hydrochlorination of acetylene to vinyl chloride. Catal. Sci. Technol. 2018, 8, 2901-2908. [CrossRef]

25. Li, X.; Pan, X.; Yu, L.; Ren, P.; Wu, X.; Sun, L.; Jiao, F.; Bao, X. Silicon carbide-derived carbon nanocomposite as a substitute for mercury in the catalytic hydrochlorination of acetylene. Nat. Commun. 2014, 5, 3688-3694. [CrossRef]

26. Zhou, K.; Li, B.; Zhang, Q.; Huang, J.Q.; Tian, G.L.; Jia, J.C.; Zhao, M.Q.; Luo, G.H.; Su, D.S.; Wei, F. The Catalytic Pathways of Hydrohalogenation over Metal-Free Nitrogen-Doped Carbon Nanotubes. ChemSusChem. 2014, 7, 723-728. [CrossRef]

27. Li, P.; Li, H.; Pan, X.; Tie, K.; Cui, T.; Ding, M.; Bao, X. Catalytically Active Boron Nitride in Acetylene Hydrochlorination. ACS Catal. 2017, 7, 8572-8577. [CrossRef]

28. Li, X.; Li, P.; Pan, X.; Ma, H.; Bao, X. Deactivation mechanism and regeneration of carbon nanocomposite catalyst for acetylene hydrochlorination. Appl. Catal. B Environ. 2017, 210, 116-120. [CrossRef]

29. Dong, X.; Chao, S.; Wan, F.; Guan, Q.; Wang, G.; Li, W. Sulfur and nitrogen co-doped mesoporous carbon with enhanced performance for acetylene hydrochlorination. J. Catal. 2018, 359, 161-170. [CrossRef] 
30. Lan, G.; Wang, Y.; Qiu, Y.; Wang, X.; Liang, J.; Han, W.; Tang, H.; Liu, H.; Liu, J.; Li, Y. Wheat flour-derived $\mathrm{N}$-doped mesoporous carbon extrudate as superior metal-free catalysts for acetylene hydrochlorination. Chem. Commun. 2018, 54, 623-626. [CrossRef]

31. Zhao, J.; Wang, B.; Yue, Y.; Sheng, G.; Lai, H.; Wang, S.; Yu, L.; Zhang, Q.; Feng, F.; Hu, Z.; Li, X. Nitrogenand phosphorus-codoped carbon-based catalyst for acetylene hydrochlorination. J. Catal. 2019, 373, $240-249$. [CrossRef]

32. Wang, B.; Zhao, J.; Yue, Y.; Sheng, G.; Lai, H.; Rui, J.; He, H.; Hu, Z.; Feng, F.; Zhang, Q. Carbon with Surface-Enriched Nitrogen and Sulfur Supported Au Catalysts for Acetylene Hydrochlorination. Chem CatChem 2019, 11, 1002-1009. [CrossRef]

33. Wittanadecha, W.; Laosiripojana, N.; Ketcong, A.; Ningnuek, N.; Praserthdam, P.; Monnier, J.R.; Assabumrungrat, $\mathrm{S}$. Preparation of $\mathrm{Au} / \mathrm{C}$ catalysts using microwave-assisted and ultrasonic-assisted methods for acetylene hydrochlorination. Appl. Catal. A Gen. 2014, 475, 292-296. [CrossRef]

34. Zhou, K.; Jia, J.; Li, C.; Xu, H.; Zhou, J.; Luo, G.; Wei, F. A low content Au-based catalyst for hydrochlorination of $\mathrm{C}_{2} \mathrm{H}_{2}$ and its industrial scale-up for future PVC processes. Green Chem. 2015, 17, 356-364. [CrossRef]

35. Tian, X.; Hong, G.; Jiang, B.; Lu, F.; Liao, Z.; Wang, J.; Yang, Y. Efficient $\mathrm{Au}^{0} / \mathrm{C}$ catalyst synthesized by a new method for acetylene hydrochlorination. RSC Adv. 2015, 5, 46366-46371. [CrossRef]

36. Zhao, J.; Gu, S.; Xu, X.; Zhang, T.; Yu, Y.; Di, X.; Ni, J.; Pan, Z.; Li, X. Supported ionic-liquid-phase-stabilized $\mathrm{Au}$ (iii) catalyst for acetylene hydrochlorination. Catal. Sci. Technol. 2016, 6, 3263-3270. [CrossRef]

37. Yin, X.; Huang, C.; Kang, L.; Zhu, M.; Dai, B. Novel $\mathrm{AuCl}_{3}$-thiourea catalyst with a low Au content and an excellent catalytic performance for acetylene hydrochlorination. Catal. Sci. Technol. 2016, 6, 4254-4259. [CrossRef]

38. Zhou, K.; Wang, W.; Zhao, Z.; Luo, G.; Miller, J.T.; Wong, M.S.; Wei, F. Synergistic Gold-Bismuth Catalysis for Non-Mercury Hydrochlorination of Acetylene to Vinyl Chloride Monomer. ACS Catal. 2014, 4, 3112-3116. [CrossRef]

39. Wittanadecha, W.; Laosiripojana, N.; Ketcong, A.; Ningnuek, N.; Praserthdam, P.; Monnier, J.R.; Assabumrungrat, S. Development of $\mathrm{Au} / \mathrm{C}$ catalysts by the microwave-assisted method for the selective hydrochlorination of acetylene. Reac. Kinet. Mech. Cat. 2014, 112, 189-198. [CrossRef]

40. Zhao, J.; Yu, Y.; Xu, X.; Di, S.; Wang, B.; Xu, H.; Ni, J.; Guo, L.; Pan, Z.; Li, X. Stabilizing Au(III) in supported-ionic-liquid-phase (SILP) catalyst using $\mathrm{CuCl}_{2}$ via a redox mechanism. Appl. Catal. B Environ. 2017, 206, 175-183. [CrossRef]

41. Nkosi, B.; Coville, N.; Hutchings, G.J.; Adams, M.; Friedl, J.; Wagner, F. Hydrochlorination of Acetylene Using Gold Catalysts: A Study of Catalyst Deactivation. J. Catal. 1991, 128, 366-377. [CrossRef]

42. Zhang, J.; He, Z.; Li, W.; Han, Y. Deactivation mechanism of $\mathrm{AuCl}_{3}$ catalyst in acetylene hydrochlorination reaction: A DFT study. RSC Adv. 2012, 2, 4814-4821. [CrossRef]

43. Zhao, J.; Xu, J.; Xu, J.; Zhang, T.; Di, X.; Ni, J.; Li, X. Enhancement of Au/AC acetylene hydrochlorination catalyst activity and stability via nitrogen-modified activated carbon support. Chem. Eng. J. 2015, 262, 1152-1160. [CrossRef]

44. Lan, G.; Yang, Y.; Wang, X.; Han, W.; Tang, H.; Liu, H.; Li, Y. Direct synthesis of mesoporous nitrogen doped $\mathrm{Ru}$-carbon catalysts with semi-embedded Ru nanoparticles for acetylene hydrochlorination. Microporous Mesoporous Mater. 2018, 264, 248-253. [CrossRef]

45. Lin, R.; Kaiser, S.K.; Hauert, R.; Pérez-Ramírez, J. Descriptors for High-Performance Nitrogen-Doped Carbon Catalysts in Acetylene Hydrochlorination. ACS Catal. 2018, 8, 1114-1121. [CrossRef]

46. Gong, W.; Zhao, F.; Kang, L. Novel nitrogen-doped Au-embedded graphene single-atom catalysts for acetylene hydrochlorination: A density functional theory study. Comput. Theor. Chem. 2018, 1130, 83-89. [CrossRef]

47. Di, X.X.; Zhao, J.; Yu, Y.; Xu, X.L.; Gu, S.C.; He, H.H.; Zhang, T.T.; Li, X.N. One-pot synthesis of nitrogen and sulfur co-doped activated carbon supported $\mathrm{AuCl}_{3}$ as efficient catalysts for acetylene hydrochlorination. Chin. Chem. Lett. 2016, 27, 1567-1571. [CrossRef]

48. Jia, Y.; Hu, R.; Zhou, Q.; Wang, H.; Gao, X.; Zhang, J. Boron-modified activated carbon supporting low-content Au-based catalysts for acetylene hydrochlorination. J. Catal. 2017, 348, 223-232. [CrossRef]

49. Zhao, J.; Xu, J.; Xu, J.; Ni, J.; Zhang, T.; Xu, X.; Li, X. Activated-Carbon-Supported Gold-Cesium(I) as Highly Effective Catalysts for Hydrochlorination of Acetylene to Vinyl Chloride. Chem. Plus Chem. 2015, 80, 196-201. [CrossRef] 
50. Zhao, J.; Zhang, T.; Di, X.; Xu, J.; Xu, J.; Feng, F.; Ni, J.; Li, X. Nitrogen-modified activated carbon supported bimetallic gold-cesium(i) as highly active and stable catalyst for the hydrochlorination of acetylene. RSC Adv. 2015, 5, 6925-6931. [CrossRef]

51. Zhang, H.; Dai, B.; Wang, X.; Li, W.; Han, Y.; Gu, J.; Zhang, J. Non-mercury catalytic acetylene hydrochlorination over bimetallic Au-Co(iii)/SAC catalysts for vinyl chloride monomer production. Green Chem. 2013, 15, 829-836. [CrossRef]

52. Zhang, H.; Dai, B.; Wang, X.; Xu, L.; Zhu, M. Hydrochlorination of acetylene to vinyl chloride monomer over bimetallic Au-La/SAC catalysts. J. Ind. Eng. Chem. 2012, 18, 49-54. [CrossRef]

53. Pu, Y.; Zhang, J.; Wang, X.; Zhang, H.; Yu, L.; Dong, Y.; Li, W. Bimetallic Au-Ni/CSs catalysts for acetylene hydrochlorination. Catal. Sci. Technol. 2014, 4, 4426-4432. [CrossRef]

54. Li, G.; Li, W.; Zhang, J. Non-mercury catalytic acetylene hydrochlorination over activated carbon-supported Au catalysts promoted by $\mathrm{CeO}_{2}$. Catal. Sci. Technol. 2016, 6, 1821-1828. [CrossRef]

55. Zhao, J.; Zhang, T.; Di, X.; Xu, J.; Gu, S.; Zhang, Q.; Ni, J.; Li, X. Activated carbon supported ternary gold-cesium(i)-indium(iii) catalyst for the hydrochlorination of acetylene. Catal. Sci. Technol. 2015, 5, 4973-4984. [CrossRef]

56. Zhao, J.; Gu, S.; Xu, X.; Zhang, T.; Di, X.; Pan, Z.; Li, X. Promotional effect of copper(ii) on an activated carbon supported low content bimetallic gold-cesium(i) catalyst in acetylene hydrochlorination. RSC Adv. 2015, 5, 101427-101436. [CrossRef]

57. Wang, S.; Shen, B.; Song, Q. Kinetics of Acetylene Hydrochlorination over Bimetallic Au-Cu/C Catalyst. Catal. Lett. 2010, 134, 102-109. [CrossRef]

58. Wang, L.; Shen, B.; Zhao, J.; Bi, X. Trimetallic Au-Cu-K/AC for acetylene hydrochlorination. Can. J. Chem. Eng. 2017, 95, 1069-1075. [CrossRef]

59. Ma, J.; Wang, S.; Shen, B. Study on the effects of acetylene on an $\mathrm{Au}-\mathrm{Cu} / \mathrm{C}$ catalyst for acetylene hydrochlorination using Monte Carlo and DFT methods. Reac. Kinet. Mech. Cat. 2013, 110, 177-186. [CrossRef]

60. Zhang, H.; Dai, B.; Li, W.; Wang, X.; Zhang, J.; Zhu, M.; Gu, J. Non-mercury catalytic acetylene hydrochlorination over spherical activated-carbon-supported $\mathrm{Au}-\mathrm{Co}(\mathrm{III})-\mathrm{Cu}$ (II) catalysts. J. Catal. 2014, 316, 141-148. [CrossRef]

61. Zhao, J.; Zeng, J.; Cheng, X.; Wang, L.; Yang, H.; Shen, B. An Au-Cu bimetal catalyst for acetylene hydrochlorination with renewable $\gamma-\mathrm{Al}_{2} \mathrm{O}_{3}$ as the support. RSC Adv. 2015, 5, 16727-16734. [CrossRef]

62. Xu, H.; Zhou, K.; Si, J.; Li, C.; Luo, G. A ligand coordination approach for high reaction stability of an Au-Cu bimetallic carbon-based catalyst in the acetylene hydrochlorination process. Catal. Sci. Technol. 2016, 6, 1357-1366. [CrossRef]

63. Du, Y.; Hu, R.; Jia, Y.; Zhou, Q.; Meng, W.; Yang, J. $\mathrm{CuCl}_{2}$ promoted low-gold-content Au/C catalyst for acetylene hydrochlorination prepared by ultrasonic-assisted impregnation. J. Ind. Eng. Chem. 2016, 37, 32-41. [CrossRef]

64. Zhao, J.; Wang, B.; Xu, X.; Yu, Y.; Di, S.; Xu, H.; Zhai, Y.; He, H.; Guo, L.; Pan, Z. Alternative solvent to aqua regia to activate $\mathrm{Au} / \mathrm{AC}$ catalysts for the hydrochlorination of acetylene. J. Catal. 2017, 350, 149-158. [CrossRef]

65. Johnston, P.; Carthey, N.; Hutchings, G.J. Discovery, Development, and Commercialization of Gold Catalysts for Acetylene Hydrochlorination. J. Am. Chem. Soc. 2015, 137, 14548-14557. [CrossRef]

66. Hong, G.; Tian, X.; Jiang, B.; Liao, Z.; Wang, J.; Yang, Y.; Zheng, J. Improvement of performance of a Au-Cu/AC catalyst using thiol for acetylene hydrochlorination reaction. RSC Adv. 2016, 6, 3806-3814. [CrossRef]

67. Horikawa, T.; Sakao, N.; Sekida, T.; Hayashi, J.i.; Do, D.D.; Katoh, M. Preparation of nitrogen-doped porous carbon by ammonia gas treatment and the effects of N-doping on water adsorption. Carbon 2012, 50, 1833-1842. [CrossRef]

68. Liu, H.; Zhang, Y.; Li, R.; Sun, X.; Désilets, S.; Abou-Rachid, H.; Jaidann, M.; Lussier, L.S. Structural and morphological control of aligned nitrogen-doped carbon nanotubes. Carbon 2010, 48, 1498-1507. [CrossRef]

69. Yang, Z.; Yao, Z.; Li, G.; Fang, G.; Nie, H.; Liu, Z.; Zhou, X.; Chen, X.; Huang, S. Sulfur-Doped Graphene as an Efficient Metal-free Cathode Catalyst for Oxygen Reduction. ACS Nano 2012, 6, 205-211. [CrossRef] 
70. Pensa, E.; Cortes, E.; Corthey, G.; Carro, P.; Vericat, C.; Fonticelli, M.H.; Benitez, G.; Rubert, A.A.; Salvarezza, R.C. The Chemistry of the Sulfur-Gold Interface: In Search of a Unified Model. Acc. Chem. Res. 2012, 45, 1183-1192. [CrossRef]

71. Li, G.; Li, W.; Zhang, J.; Zhang, W.; Zhou, H.; Si, C.L. The Effect of N-Doping in Activated Carbon-Supported Au-Sr Catalysts for Acetylene Hydrochlorination to Vinyl Chloride. ChemistrySelect 2018, 3, 3561-3569. [CrossRef]

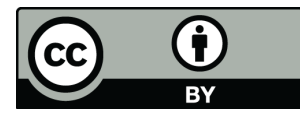

(C) 2019 by the authors. Licensee MDPI, Basel, Switzerland. This article is an open access article distributed under the terms and conditions of the Creative Commons Attribution (CC BY) license (http://creativecommons.org/licenses/by/4.0/). 